\title{
Religiousity and Risky Sexual Behaviour among Undergraduates in South West Nigeria
}

\author{
Olayinka Stephen llesanmi
}

\author{
Department of Community Health, Federal Medical Centre, Owo, Ondo State, Nigeria \\ E mail: ileolasteve@yahoo.co.uk \\ Olusimbo Kehinde Ige \\ Department of Community Medicine University College Hospital, Ibadan, Oyo State Nigeria \\ Faith Osaretin Alele \\ Department of Community Health, Federal Medical Centre, Owo, Ondo State, Nigeria
}

\section{Doi:10.5901/mjss.2014.v5n23p2345}

\section{Abstract}

This study aimed to explore the relationship spirituality and religion had on sexual behaviour and experiences. A crosssectional analytical survey involving 215 undergraduates from three tertiary institutions was conducted. These students were interviewed while on rural health practicum in a town in south west Nigeria. Spirituality was assessed with 9 questions having dichotomous responses. Maximum obtainable score was 18. Scores above the mean were classed as high spirituality. Mean age of respondents was $23.1 \pm 3.7$ years, $59.1 \%$ were female, and $78.1 \%$ were Christian while $11.9 \%$ were Muslims. In all, $54.4 \%$ were sexually active. Among the sexually active 76(65\%) were involved in Risky Sexual Behaviour (RSB). Spirituality/faith was an important part of the lives of $92.6 \%$ while $80 \%$ considered themselves to be moderately or very spiritual. Religious practices were reported on a daily basis by $83.7 \%$. The mean age at sexual initiation was $17 \pm 5.2 y e a r s$. Less than half (49\%) had multiple sexual partners, 22\% received gifts for sex, 53\% did not use condom at last sex, and $22 \%$ had unwanted pregnancy while 9\% had Sexually Transmitted Infections (STI). Logistic regression analysis revealed that spirituality had no influence on sexual risk behaviour. Many students were sexually active and a high proportion exhibited RSB. Sustainable sexual health responses targeted at reducing risk behaviour among young people should not be limited by perceived spirituality.

Keywords: spirituality; religiousity; sex; sexual health; risky sexual behaviour

\section{Introduction}

A number of factors are involved in the evolution of sexual attitudes and behaviour, such as one's personal philosophy about life (e.g., spirituality), exposure to sexual content (e.g., experience with sexual content or behavior), or moral teaching learned from parents, peers, or society (e.g., religious background, culture and societal norms). (Barnett et al., 2010, Steinman and Zimmerman, 2004) The assumption can also be made that there are a combination of these factors that bring about a person's understanding of what he or she believes about sex and how he or she will approach sexual behaviour. (Hardy and Raffaelli, 2003) Religiosity is a crucial factor which has a significant effect on sexual initiation among young people. It has been measured by the level of spirituality, the frequency of religious attendance and level of involvement in religious activities. (Beckwith and Morrow, 2005, Bankole and Malarcher, 2010)

Young people face pressures which cause them to exhibit risky sexual behaviours such as early sexual initiation, casual unprotected sex and multiple sexual partners, with resultant consequences such as sexually transmitted infections, HIVIAIDs, unwanted pregnancies, abortions and adolescent parenting. (Morhason-Bello et al., 2008, WHO) Adolescence as defined by WHO is the period in human growth and development that occurs after childhood and before adulthood, from ages 10 to19(UNESCO) while young people are defined by the United Nations as persons between the ages of 15 and 24 and the experiences of these groups of persons vary from country to country.(WHO, 2010)

Nigeria, the most populous country in Africa has at least one in 3 African adolescent living within her.(USAID, 2009) It has one of the highest birth rates for adolescents in the world with an increasing prevalence of sexually transmitted infections and HIV and this may be due to poverty and high rates of unemployment.(Bernstein and Hansen, 2006) There is an intricate relationship between poverty and reproductive health. Young women often engage in these 
risky behaviours such as unsafe sex in exchange for monetary incentives. Promotion of abstinence and suppression of sexual desire is the teaching of many of the religious groups in Nigeria.(National Population Commission (NPC) [Nigeria] and Macro, 2009)

According to the 2008 Nigeria Demographic and Health Survey (NDHS) most Nigerians are involved in the two popular religious groups (Christianity $=54 \%$ and Islam $=44 \%$ ) while only $2 \%$ fall into no religious or traditional category. There are several diverse denominations or sects which have sprung up in the last three decades among the two popular religious groups- Christianity and Islam - but are more obvious among the Christian religious group in all nooks and crannies of the country.(Durojaiye, 2008) Despite the fact that these risky sexual behaviours such as premarital sexual practices are prohibited by these religions, young people are not refraining from such practices.(Morhason-Bello et al., 2008) Many of them have low or inaccurate knowledge of sexual and reproductive health, and have very little use of family planning or other protective measures.(Okonofua, 2007) The apparent pervasive religiosity in the country makes it difficult for these young people to access and accept help or interventions that have been used to abate these similar issues in the western part of the world.(Pargament and Mahoney, 2002)

The role of religion in regulating sexual behaviour is complex and has far-reaching implications. It is a broadly-held religious belief that sexual desires ought to be repressed. Some roles that religion play in regulating sexual behaviour have clear social and cultural benefits, however the influence of spirituality and religion on sexual behaviour and experiences is yet to be fully explored. It is therefore of a necessity to explore the effect of both religion and its function (spirituality) on sexual behaviour among young adults in Nigeria.(Ball et al., 2003)

\section{Methods}

The study was a cross-sectional analytical survey involving 215 undergraduates from three tertiary institutions. All the institutions are in Oyo State, Nigeria. These students were interviewed while on rural health practicum in a town in south west Nigeria.

Self-administered questionnaire was used to collect information from the students. Section A of the questionnaire contained sociodemographic characteristics of the respondents' their age, sex, marital status, present religion and religion while growing up. Section B contained frequency of religious experiences. A single general question was asked to assess level of spirituality, response was in four categories. Questions were also asked to determine the respondents age at sexual debut.

The following questions were asked with yes/no responses

1. Do you believe in God or higher power?

2. Do you have important religious experiences and thoughts?

3. Do you see your relationship with God as personal?

4. Do you follow a spiritual path or practice?

5. Do you have special spiritual experiences?

6. Do you pray often?

7. Has prayer worked for you?

8. Has your prayer been answered?

9. Do you apply spirituality to situations of life?

The main outcome measure used in these analyses examined how many different types of risky behaviour the person reported practices. Occurrence of risky sexual behaviour among the sexually active was determined using the following questions. A positive response to at least one of the questions was classified as sexual risk behaviour:

1. Do you have multiple short-term sexual encounters?

2. Have you ever received gifts for sex?

3. Did you use condom at last sex?

4. Have you ever had unwanted pregnancy?

5. Have you had Sexually Transmitted Diseases? Questions like past itching of the genitals and discharge within two week of sex without the use of condom were used to support it.

\section{Data Analysis}

Data was entered, cleaned and analyzed using Statistical Package for Social Sciences version 15 software. Frequencies and proportions were used to summarize variables of interest. Spirituality was assessed with 9 questions with dichotomous responses. Maximum obtainable score was 18. Scores above the mean were classed as high spirituality 
while scores from the mean and below were classified as low spirituality. Chi-square test and fisher's exact test were used to find the association between Socio demographic characteristics and risky sexual behaviour and Religious experiences and risky sexual behaviour. Logistic regression was done. The dependent variable on the logistic regression model was risky sexual behaviour while the independent were sex, age, religion and spirituality level. Odds ratios (OR), $95 \%$ confidence intervals $(\mathrm{Cl})$ and $p$-value were presented. In all analysis the level of significance was set at 0.05 , twotailed.

\section{Results}

Table 1: Frequency of demographic characteristics of respondents

\begin{tabular}{ccc}
\hline Variable & N & $(\%)$ \\
\hline Age & & \\
<25 years & 164 & 76.3 \\
$\geq 25$ years & 51 & 23.7 \\
Sex & 88 & 40.9 \\
Male & 127 & 59.1 \\
$\quad$ Female & & \\
Marital status & 206 & 95.8 \\
$\quad$ Single & 9 & 4.2 \\
$\quad$ Married & & \\
Present Religion & 168 & 78.1 \\
$\quad$ Christianity & 47 & 21.9 \\
$\quad$ Islam & & \\
Religion while growing up & 207 & 96.3 \\
Christianity \\
Islam
\end{tabular}

Table 2: Frequency of religious experiences among respondents

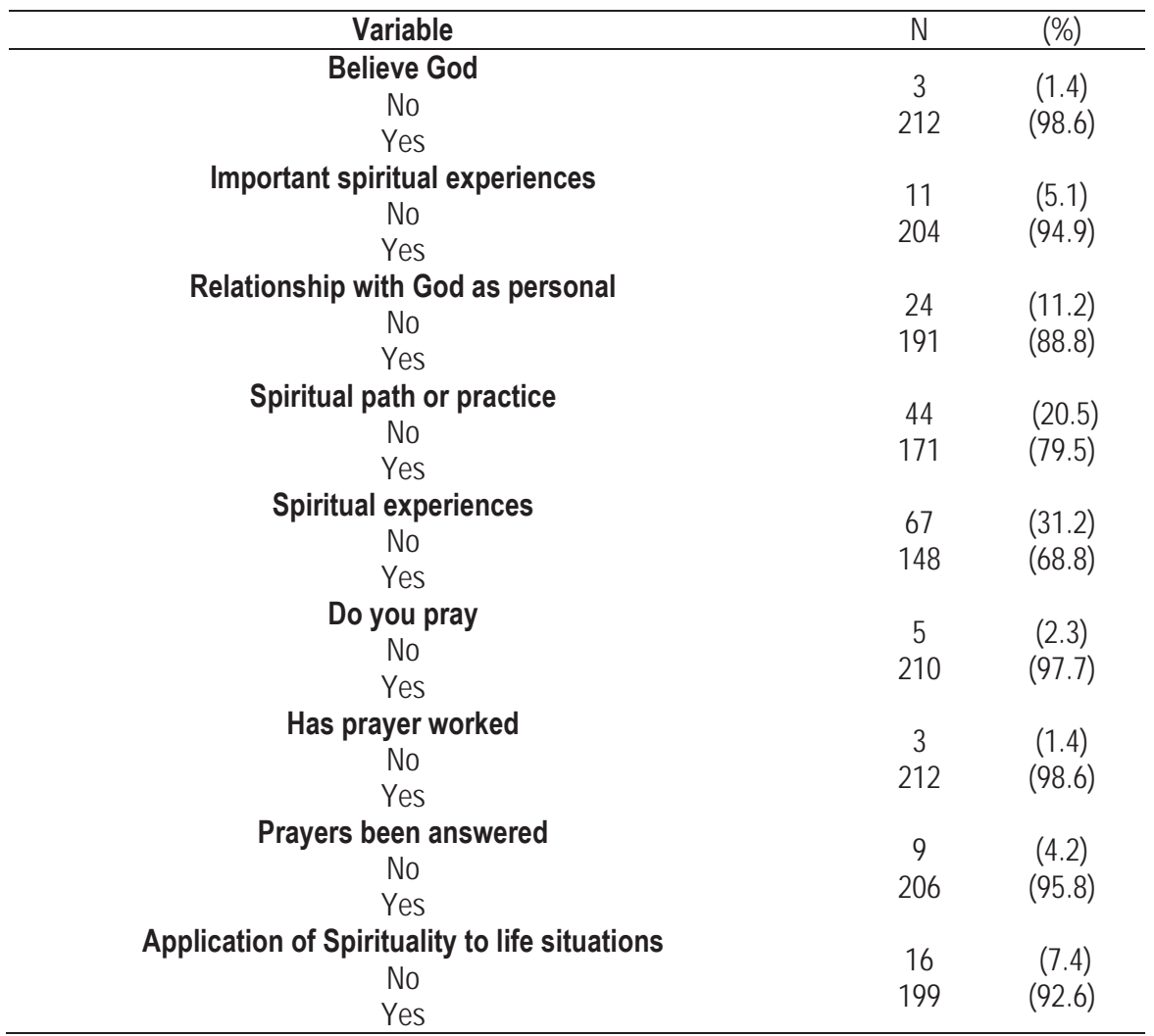




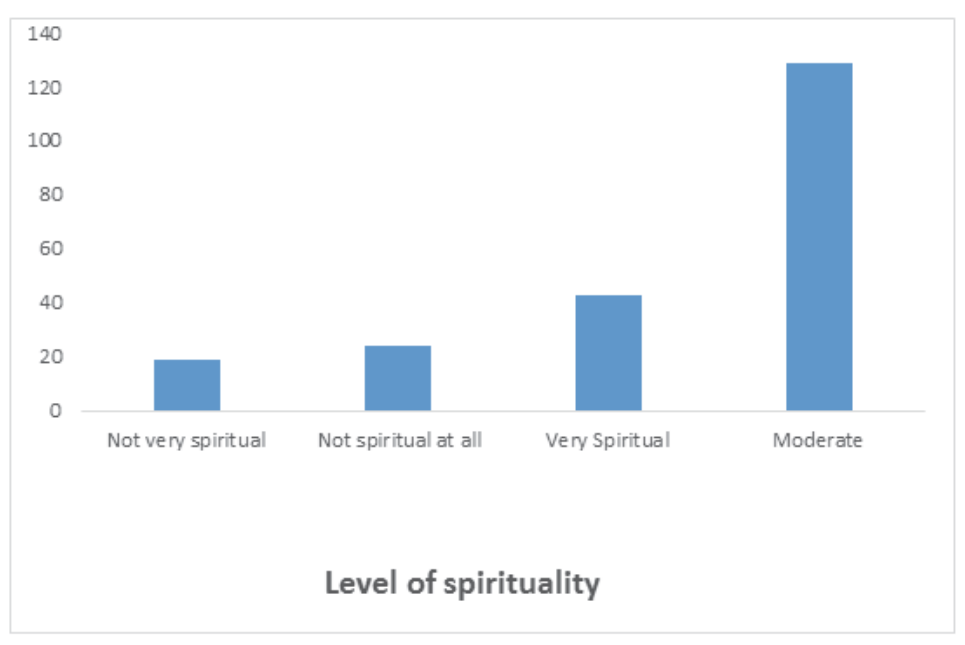

Figure 1: Self reported level of spirituality

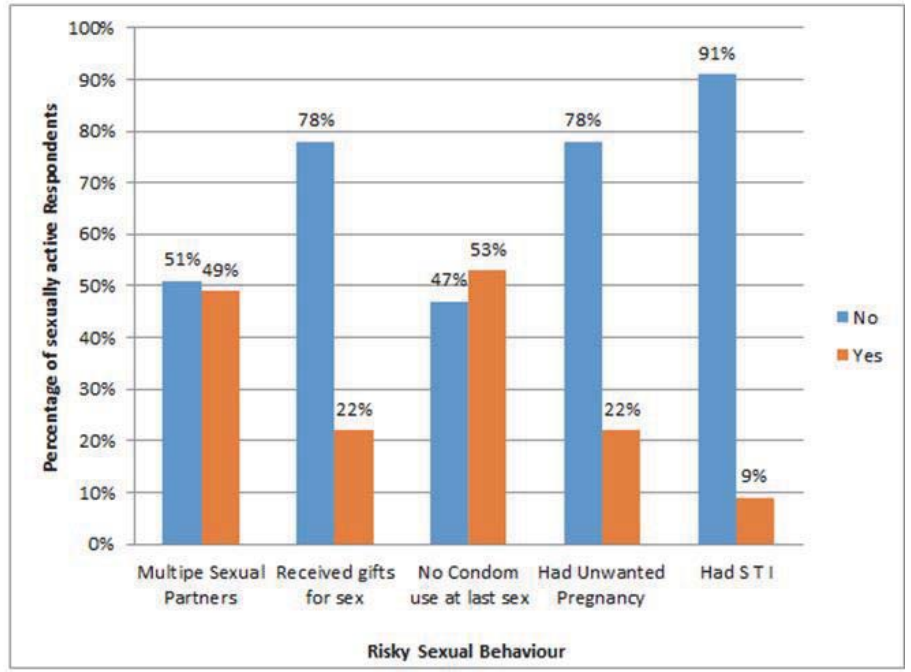

Figure 2: Showing risky sexual behaviours among sexually active respondents

Table 3: Sociodemographic characteristics and risky sexual behaviour

\begin{tabular}{|c|c|c|c|c|}
\hline \multirow[t]{2}{*}{ Characteristics } & \multicolumn{2}{|c|}{ Risky Sexual Behaviour } & \multirow[t]{2}{*}{ Chi-square } & \multirow[t]{2}{*}{ P-value } \\
\hline & Present (\%) & Absent (\%) & & \\
\hline \multicolumn{5}{|l|}{ Age } \\
\hline$<25$ years & $61(70.1)$ & $26(29.9)$ & 3.965 & 0.046 \\
\hline$\geq 25$ years & $15(50.0)$ & $15(50.0)$ & & \\
\hline \multicolumn{5}{|l|}{ Sex } \\
\hline Male & $36(69.2)$ & $16(30.8)$ & 0.751 & 0.386 \\
\hline Female & $40(61.5)$ & $25(38.5)$ & & \\
\hline \multicolumn{5}{|l|}{ Marital Status } \\
\hline Single & $72(66.7)$ & $36(33.3)$ & 1.802 & 0.179 \\
\hline Married & $4(44.4)$ & $5(55.6)$ & & \\
\hline \multicolumn{5}{|l|}{ Religion } \\
\hline Christianity & $55(63.2)$ & $32(36.8)$ & 0.451 & 0.502 \\
\hline Islam & $21(70.0)$ & $9(30.0)$ & & \\
\hline
\end{tabular}


Table 4: Religious experiences and risky sexual behaviour

\begin{tabular}{|c|c|c|c|c|}
\hline \multirow[t]{2}{*}{ Religious experiences } & \multicolumn{2}{|c|}{ Risky Sexual Behaviour } & \multirow[t]{2}{*}{ Chi-Square } & \multirow[t]{2}{*}{ P-value } \\
\hline & Present (\%) & Absent $(\%)$ & & \\
\hline \multicolumn{5}{|l|}{ Believe God } \\
\hline Yes & $74(64.9)$ & $40(35.1)$ & 0.004 & 0.950 \\
\hline NO & $2(66.7)$ & 1(33.3) & & \\
\hline \multicolumn{5}{|c|}{ Have important spiritual experiences } \\
\hline Yes & $70(64.2)$ & $39(35.8)$ & 0.380 & 0.530 \\
\hline No & $6(75.0)$ & $2(25.0)$ & & \\
\hline \multicolumn{5}{|c|}{ Have personal relationship with God } \\
\hline Yes & $67(66.3)$ & $34(33.7)$ & 0.617 & 0.432 \\
\hline No & $9(56.3)$ & $7(43.8)$ & & \\
\hline \multicolumn{5}{|c|}{ Have spiritual path or practice } \\
\hline Yes & $57(64.8)$ & $31(35.2)$ & 0.005 & 0.942 \\
\hline NO & $19(65.5)$ & $10(34.5)$ & & \\
\hline \multicolumn{5}{|c|}{ Have any spiritual experiences } \\
\hline Yes & $54(66.7)$ & $27(33.3)$ & 0.338 & 0.561 \\
\hline No & $22(61.1)$ & $14(38.9)$ & & \\
\hline \multicolumn{5}{|l|}{ Praying always } \\
\hline Yes & $74(65.5$ & $39(34.5)$ & 0.407 & 0.523 \\
\hline No & $2(50)$ & $2(50)$ & & \\
\hline \multicolumn{5}{|l|}{ Prayer worked for you } \\
\hline Yes & $76(66.1)$ & $39(33.9)$ & Fishers exact test & 0.121 \\
\hline No & $0(0)$ & $2(100)$ & & \\
\hline \multicolumn{5}{|l|}{ Prayer been answered } \\
\hline Yes & $72(66.1)$ & $37(33.9)$ & 0.844 & 0.358 \\
\hline No & $4(50)$ & $4(50)$ & & \\
\hline \multicolumn{5}{|c|}{ Having spirituality or faith in life } \\
\hline Yes & $68(65.4)$ & $36(34.6)$ & 0.075 & 0.784 \\
\hline No & $8(61.8)$ & $5(38.5)$ & & \\
\hline \multicolumn{5}{|l|}{ Overall level of spirituality } \\
\hline High & $37(61.7)$ & $23(38.3 \%)$ & 0.586 & 0.444 \\
\hline Low & $39(68.4)$ & $18(31.6)$ & & \\
\hline
\end{tabular}

Table 5: Predictors of risky sexual behaviours

\begin{tabular}{cccc}
\hline Variable & Odd Ratio & Confidence Interval & p-value \\
\hline Sex & 1.48 & $0.645-3.395$ & 0.356 \\
Male & 1 & & \\
Female & Age & $1.017-6.026$ & 0.046 \\
24 years and below & 2.48 & & \\
25 years and above \\
Religion \\
$\begin{array}{c}\text { Christianity } \\
\text { Islam }\end{array}$ & 1 & $0.230-1.863$ & 0.427 \\
$\begin{array}{c}\text { Spirituality level } \\
\text { Low spirituality }\end{array}$ & 0.654 & & 0.522 \\
High Spirituality & 1 & $0.238-2.075$ & \\
\hline
\end{tabular}

The mean age of respondents was $23.1 \pm 3.7$ years and more than half (59.1\%) were females. $95.8 \%$ were single, $78.1 \%$ were Christians while $96.3 \%$ practiced Christianity as a religion while growing up. Out of the 215 students who participated 117(54.4\%) were sexually active. Among the sexually active 76(65\%) were involved in Risky Sexual Behaviour (RSB). The mean age at sexual initiation was $17 \pm 5.2$ years.

Mean spirituality score was $17.15 \pm 1.3$. Using the mean spirituality score, those who were spiritual by scoring above the mean were 115(53.5) while 110(46.5\%) were not spiritual. Table 2 shows frequency of religious experiences 212(98.6\%) believed in God while 191(88.8\%) had a personal relationship with God, 212 (98.6\%) said prayer had worked 
for them and 206(95.8\%) have had their prayers answered. Figure 1 shows the self-reported level of spirituality among the respondents which revealed that about 129 of the respondents had moderately high level of spirituality while 24 were not spiritual at all.

Figure 2 shows risky sexual behaviour among the sexually active respondents, $49 \%$ had multiple sexual partners, $22 \%$ received gifts for sex, 53\% did not use condom at last sex, and 22\% had unwanted pregnancy while $9 \%$ had Sexually Transmitted Infections (STI). Table 3 shows the association between socio demographic characteristics and risky sexual behaviour, respondents who are $<25$ years of age are more likely to participate in risky sexual behaviour compared to respondents who are $\geq 25$ years $(p=0.046)$. Table 4 shows the association between religious experiences and risky sexual behaviour, 76 (66.1\%) of the respondents who believed that prayer had worked for them participated in risky sexual behaviour.

Table 5 shows the predictors of risky sexual behaviours, the only significant factor predicting risky sexual behaviour is age [OR=2.48(1.017-6.026)] $\mathrm{P}=0.046$. Spirituality had no significant effect on risky sexual behaviour of the respondents $[\mathrm{OR}=0.702(0.238-2.075)] \mathrm{P}=0.522$

\section{Discussion}

Religion has been found to be protective against risky sexual behaviour and has an important influence in the lives of young people.(Birndorf et al., 2005) Sexual risk-taking involves inconsistent condom use or the absence of its use as well as having multiple sexual partners and serial monogamy.(Kaestle and Halpern, 2007) However, most young people participate in these risky sexual behaviours such as inconsistent condom use and oral and anal sex which places them at risk of sexually transmitted infections and other negative health implications either to maintain an intimate relationship or for exchange of gifts and in most cases due to peer pressure. Thus negotiation of sexual activity remains a persistent challenge.(Garwick et al., 2004, Onipede, 2011)

The mean age at sexual initiation for the studied population was $17 \pm 5.2$ years which is similar to a study carried out among students in a university in south east United States with a mean age of sexual debut to be 17 years.(Tana, 2005) Another similar study was conducted among adolescents in Lagos which showed that most of the respondents had their first sexual intercourse at age 14 and above. The level of spirituality was moderately high among the respondents in the studied population which is also similar to the study conducted among adolescents in Lagos, Nigeria.(Beckwith and Morrow, 2005)

Spirituality had no significant effect on risky sexual behaviour among the respondents in the studied population; this is in contrast to a study conducted among college students from a south eastern doctoral research university which showed that there was a negative relationship between spirituality and sexual attitudes suggesting that students who tend to hold core spiritual beliefs, such as the belief in the importance of actively pursuing a spiritual life or who have had significant spiritual experiences that has changed the person's life, are likely to possess less sexually permissive attitudes about sex and tend to hold more conservative, traditional views about sexual practices.(Holder et al., 1999, Tana, 2005)

The results showed that students who had core spiritual beliefs/experiences or who were highly spiritual were more likely to participate in risky sexual behaviours and this is in contrast to a study where a dimension of spirituality (i.e., interpersonal relationships within a body of faith) was significantly related to fewer voluntary sexual experiences.(Holder et al., 1999) This is also in contrast to a study conducted among American adolescents which showed that adolescents who frequently attended church and church youth activities, prayed often, and said religion was important to them were less likely to report ever having had sex.(James et al., 2003)

\section{Conclusions and Recommendations}

Many students were sexually active and a high proportion exhibited risky sexual behavior. The common belief that spirituality modulates sexual behavior was not evident in this study. Sustainable responses targeted at reducing risk behavior among young people while being sensitive to spirituality and religiosity should not be limited by perceived spirituality values.

\section{References}

Ball, J., Armistead, L. \& Austin, B. J. 2003. The relationship between religiosity and adjustment among African-American, female, urban adolescents. . Journal of Adolescence, 26, 431-446.

Bankole, A. \& Malarcher, S. 2010. Removing barriers to adolescents' Access to contraceptive information and services. Studies in 
Family Planning, 41, 117-124.

Barnett, R. V., Jackson, T. L., SMITH, S. \& GIBSON, H. 2010. The effects of religiosity and sibling relationship on the timing of sexual debut. Family Science Review, 15, 66-83.

Beckwith, H. D. \& Morrow, J. A. 2005. Sexual Attitudes of College Students: The Impact of Religiosity and Spirituality. College Student Journal, 39.

Bernstein, S. \& HANSEN, C. 2006. Public choices, private decisions: Sexual and reproductive health and the Millennium Development Goals. [Online]. Available: www.unmillenniumproject.org [Accessed 22/02/2014 2014].

Birndorf, S., Ryan, S., Auinger, P. \& Aten, M. 2005. High self-esteem among adolescents: longitudinal trends, sex differences, and protective factors. Journal of Adolescent Health, 37, 194-201.

Durojaiye, C. 2008. Knowledge, Perception and Behaviour of Nigerian Youths on HIVIAIDS. The Internet Journal of Health, 9.

Garwick, A., Nerdahl, P., Banken, R., Muenzenberger- Bretl, L. \& SIEVING, R. 2004. Risk and protective factors for sexual risk taking among adolescents involved in Prime Time. Journal of Pediatric Nursing, 19, 340-350.

Hardy, S. A. \& RAFFAELLI, M. 2003. Adolescent religiosity and sexuality: an investigation of reciprocal influences. Journal of Adolescence, 26, 731-739.

Holder, D. W., Durant, R. H., Harris, T. L., Daniel, J. H., Obeidallah, D. \& Goodman, E. 1999. The association between adolescent spirituality and voluntary sexual activity. Journal of Adolescent Health, 26, 295-302.

James, M. N., Clea, A. M. \& Robert, W. B. 2003. Evidence from the National Longitudinal Study of Adolescent Health,"Public and Private Domains of Religiosity and Adolescent Health Risk Behaviors. Social Science and Medicine,, 57, 2049-2054.

Kaestle, C. E. \& Halpern, C. T. 2007. What's Love Got to Do with IT? Sexual Behaviors of Opposite Sex Couples through Emerging Adulthood. Perspectives on Sexual and Reproductive Health, 39, 134-140.

Morhason-Bello, I. O., Oladokun, A., Enakpene, C. A., Fabamiro, A. O., Obisesan, K. A. \& Ojengbede , O. A. 2008. Sexual behaviour of in-school adolescents in Ibadan, South-West Nigeria. African Reproductive Health, 12, 89-97.

National Population Commission (NPC) [Nigeria] \& Macro, I. C. F. (eds.) 2009. Nigeria Demographic and Health Survey 2008, Abuja, Nigeria: National Population Commission and ICF Macro.

Okonofua, F. 2007. New research findings on adolescent reproductive health in Africa. African Journal of Reproductive Health, 11, 7-9.

Onipede, W. 2011. Religion, religiosity and adolescent risky sexual health behaviour in Lagos Metropolis, Nigeria. Journal of Human and Social Sciences, 3, 48-55.

Pargament, K. I. \& Mahoney, A. 2002. Spirituality: Discovering and conserving the sacred. In Handbook of positive psychology In: Snyder, C. R. \& Lopez, S. J. (eds.). New York: Oxford University Press.

Steinman, K. S. \& Zimmerman, M. A. 2004. Religious activity and risky behaviour among African American adolescents: Concurrent and developmental effects. American Journal of Community Psychology, 33, 151-161.

Tana, L. J. 2005. Effects of sibling relationships and religiosity on the timing of sexual debut. Master of Science, University of Florida

UNESCO. Acting with and for the youth [Online]. Available: www.unesco.org [Accessed 12/2/2014 2014].

USAID. 2009. Healthy Policy initiative; Facts sheet on youth reproductive health policy [Online]. Available: www.healthpolicyinitiative.com [Accessed 12/02/2014 2014].

Who. Maternal, new born, child and adolescent health: Adolescent development [Online]. Available: www.who.int [Accessed 12/02/2014 2014].

Who. 2010. Nigeria: country progress report [Online]. Available: www.who.int [Accessed 12/02/2014 2014]. 